\title{
Lesões olfatórias pós-traumáticas
}

\author{
Luiz Fernando Cannoni ${ }^{1}$, Luciano Haddad ${ }^{1}$, Nelson Saade ${ }^{1}$, José Carlos Esteves Veiga ${ }^{2}$ \\ Faculdade de Ciências Médicas da Santa Casa de São Paulo, São Paulo, SP, Brasil.
}

\section{RESUMO}

Objetivo: Documentar a incidência de lesões traumáticas do nervo olfatório, assim como a etiologia traumática; correlacionar as lesões do nervo olfatório com achados radiológicos (lesões cranianas e intracranianas) e estudar lesões múltiplas de nervos cranianos. Métodos: Vinte e quatro pacientes admitidos no Serviço de Emergência da Santa Casa de Misericórdia de São Paulo com lesão traumática do nervo olfatório foram incluídos. Os pacientes foram divididos em três grupos, de acordo com o escore da escala de coma de Glasgow (ECG): trauma leve (ECG de 13 a 15), moderado (ECG de 9 a 12) e grave (ECG de 3 a 8), assim como em diferentes graus de lesão do olfatório, como hiposmia, anosmia e parosmia, distribuição quanto a gênero, presença de fraturas, lesões intracranianas, fístulas liquóricas e mecanismo de trauma. Resultados: Dos 24 casos, 15 lesões ocorreram em conjunto com outros nervos cranianos e em nove casos houve lesão exclusiva do nervo olfatório. $O$ atropelamento foi a causa mais comum de lesão do nervo olfatório de forma isolada, assim como nas lesões de múltiplos nervos. Hematomas extradurais foram as lesões intracranianas mais frequentes e a ausência de fraturas predominou nos indivíduos estudados. Conclusão: Neuropatia traumática do olfatório deve ser pesquisada na admissão do paciente (quando possível), sobretudo quando houver evidência de traumas frontais ou occipitais.

\section{PALAVRAS-CHAVE}

Traumatismos dos nervos cranianos, traumas craniocerebrais, nervo olfatório.

\section{ABSTRACT}

Post traumatic olfactory lesions

Objective: To register the incidence of the traumatic lesions to the olfactory nerve and its etiology; to correlate these lesions to the radiological findings (cranial and intracranial) and study multiple cranial nerve lesions. Methods: Twenty-four patients admitted to the Emergency Service of Santa Casa de Misericórdia de São Paulo Hospital have been studied and lesions to the olfactory nerves were described. The patients were divided into three groups according to the Glasgow coma scale (GCS) in: mild trauma (GCS: 13 to 15), moderate (GCS: 9 to 12) and severe (GCS: 3 to 8) and into different groups depending on the degree of the nerve (anosmia, hiposmia and parosmia), gender, fractures, intracranial lesions, CSF fistulas and type of trauma. Results: Posttraumatic single nerve lesion was observed in 9 patients and in 15 patients multiple nerve lesions associated with the olfactory nerve lesion were documented. Running over was the main cause of these lesions (single nerve and multiple nerves). Extradural hematomas were the most frequent intracranial lesions and the absence of cranial fractures were dominant. Conclusion: Traumatic olfactory neuropathy occurs must be searched on the patient admission (whenever it is possible), especially in those cases in that frontal or occipital fractures are present.

\section{KEYWORDS}

Cranial nerve injuries, craniocerebral trauma, olfactory nerve.

\section{Introdução}

A lesão isolada ou combinada de nervos cranianos é achado relativamente frequente quando decorrente de traumatismo cranioencefálico (TCE). De acordo com Patel et al., ${ }^{1}$ em 12,6\% dos casos de TCE ocorreram lesões dos diferentes nervos cranianos, com nítido predomínio de acometimento no gênero masculino e traumas resultantes de mecanismos de baixa energia cinética.

São lesões frequentemente despercebidas nos exames neurológicos de entrada em prontos- 
-socorros e muitas vezes somente perceptíveis ou evidentes tardiamente durante a evolução do processo traumático. ${ }^{2}$ Pacientes comatosos podem ter lesões traumáticas de nervos cranianos e, por causa do comprometimento do nível de consciência, essas lesões podem não ser detectadas. Exceções se fazem aos nervos oculomotor (III), abducente (VI) e facial (VII), que evidenciam lesão sem a colaboração do paciente.

Existem algumas "armadilhas" quanto ao diagnóstico de lesão de nervos cranianos; por exemplo, a perda de olfação pode ocorrer por simples obstrução nasal, e não lesão própria em nervo olfatório; o bloqueio do canal auditivo externo ou a lesão da orelha média podem causar diminuição da acuidade auditiva sem lesão do oitavo nervo.

As lesões traumáticas podem decorrer de forças de cisalhamento, aceleração e desaceleração, lesões penetrantes, traumas diretos com fraturas cranianas e como sequelas de procedimentos cirúrgicos.

Os objetivos deste trabalho foram: documentar a incidência de lesões do nervo olfatório associadas a TCE; correlacionar as lesões com achados radiológicos (fraturas, afundamentos e lesões intracranianas) e etiologia traumática (atropelamentos, acidentes automobilísticos etc.); relatar a distribuição de frequência das lesões isoladas e múltiplas associadas à lesão do nervo olfatório, identificando quais as associações de lesões são mais frequentes; correlacionar a incidência de fístula liquórica com a presença de lesão de nervo olfatório e revisar a literatura.

\section{Casuística e método}

Estudaram-se 24 casos de lesões traumáticas de nervo olfatório em pacientes atendidos no ProntoSocorro Central da Santa Casa de Misericórdia de São Paulo, no período de junho de 2010 a junho de 2012, por meio de estudo prospectivo com base em protocolo próprio, previamente autorizado pelo Comitê de Ética da instituição. Os pacientes foram subdivididos em grupos conforme os critérios a seguir:

- quanto à distribuição por gênero;

- quanto à intensidade do trauma, de acordo com a escala de coma de Glasgow (ECG) na admissão, em trauma leve (ECG de 13 a 15), moderado (ECG de 9 a 12) e grave (ECG de 3 a 8$)$;

- quanto à presença de fraturas ou afundamentos cranianos;
- quanto à forma da lesão traumática;

- quanto à presença ou ausência de lesões intracranianas;

- quanto à presença ou ausência de fístula liquórica traumática.

O exame neurológico dos nervos cranianos foi feito na admissão, assim como durante o período de internação e no seguimento ambulatorial.

Como critérios de lesão, incluíram-se os seguintes achados para lesão do nervo olfatório: hiposmia (detecção de odor com impossibilidade de reconhecimento da fonte odorífera) uni ou bilateral; anosmia (não detecção de qualquer odor) uni ou bilateral; parosmia (detecção do odor de forma errônea); cacosmia (percepção extremamente desagradável do estímulo olfatório); fantosmia (intermitência ou persistência da sensação olfativa na ausência de estímulo externo). Foram oferecidas substâncias comumente conhecidas pelos pacientes como café, hortelã e canela. Foram evitadas substâncias ácidas e voláteis sob pena de estimular terminais trigeminais e provocar irritação da mucosa nasal.

Os pacientes são seguidos em âmbito ambulatorial em períodos regulares e avaliados sempre pelo autor.

\section{Resultados}

Dos 24 casos estudados, apenas nove $(37,50 \%)$ tiveram lesão exclusiva de nervo olfatório, enquanto $15(62,50 \%)$ casos apresentaram lesão associada a outros nervos cranianos (Tabela 1 ).

Houve nítido predomínio das lesões no gênero masculino ( 22 casos - 91,67\%), enquanto o gênero feminino correspondeu a duas pacientes $(8,33 \%)$.

\begin{tabular}{lcc}
\hline \multicolumn{2}{c}{$\begin{array}{c}\text { Tabela } 1 \text { - Distribuição de frequência } \\
\text { olfatório }\end{array}$ associada } & à lesães do nervo \\
Nervos lesados & Número de lesões & Porcentagem \\
\hline I/VIII & 5 & $33,33 \%$ \\
I/II & 2 & $13,33 \%$ \\
I/II/V & 2 & $13,33 \%$ \\
I/II/VIII & 2 & $13,33 \%$ \\
I/II/III & 1 & $6,66 \%$ \\
I/II/III/V & 1 & $6,66 \%$ \\
I/II/III/V/VI/VII/VI & 1 & $6,66 \%$ \\
I/V/VI & 1 & $6,66 \%$ \\
Total & 15 & $100 \%$ \\
\hline I: nervo olfatório; II: nervo óptico; III: nervo oculomotor; IV: nervo troclear; V: nervo
\end{tabular}

trigêmeo; VI: nervo abducente; VII: nervo facial; VIII: nervo vestíbulo-coclear. 
Atropelamentos e quedas de alturas (escadas e lajes) representaram a etiologia mais frequente na lesão do nervo olfatório (Figura 1), além de três casos de acidente automobilístico e três casos de acidente motociclístico.

Quando presentes, as fraturas parietais e occipitais predominaram (Figura 2), por vezes dirigindo-se à região mastoide e contribuindo com lesão adicional do VII ou VIII nervos.

Quatro pacientes não apresentaram fraturas cranianas detectáveis aos métodos investigativos (radiografia simples e tomografia de crânio).

Dois casos de hiposmia estavam relacionados com a presença de fístula liquórica nasal.

Oito pacientes foram admitidos com escore 15 na ECG e seis com escore igual a 14 . Anosmia e parosmia predominaram nesses pacientes (Figura 3).
Os hematomas extradurais ocorreram em sete casos, seguidos de três pacientes com hemorragia subaracnoide traumática e quatro contusões cerebrais. Em quatro pacientes não houve lesão intracraniana. Com a presença de hematomas extradurais, observaram-se anosmia e hiposmia como lesões predominantes (Figura 4).

Em termos de lesões de nervos associadas, a mais frequente foi a lesão do I nervo com o VIII nervo (Tabela 1). Anosmia foi presenciada em 15 pacientes $(62,5 \%)$, seguida de oito casos de hiposmia $(33,33 \%)$ e 1 caso de parosmia $(4,17 \%)$ (Figura 5).

Os pacientes com comprometimento do nível de consciência tiveram o diagnóstico de lesão olfatória durante o acompanhamento ambulatorial e esses pacientes sabidamente não apresentavam tais lesões previamente ao trauma.

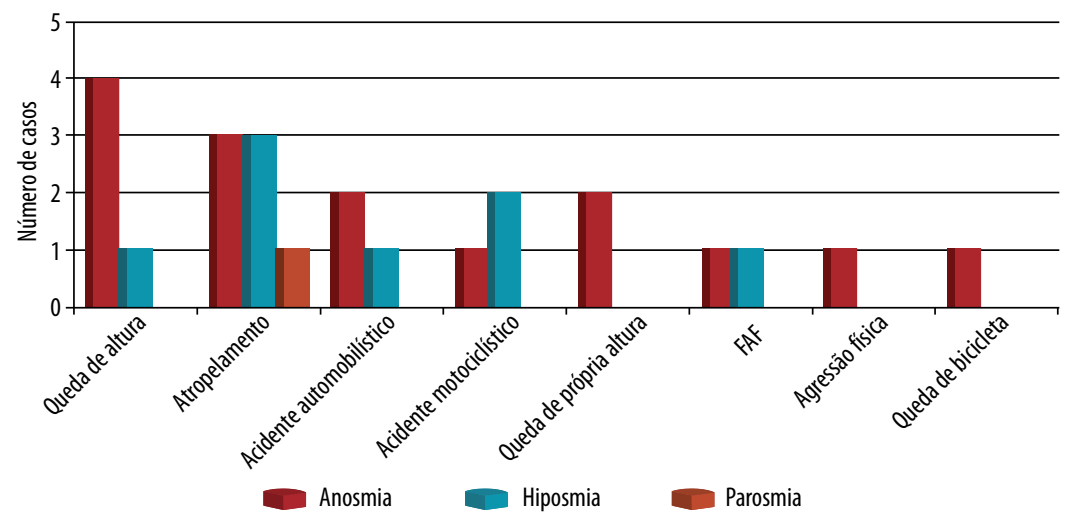

Figura 1 - Distribuição de frequência da etiologia traumática. FAF: ferimento por projétil de arma de fogo.

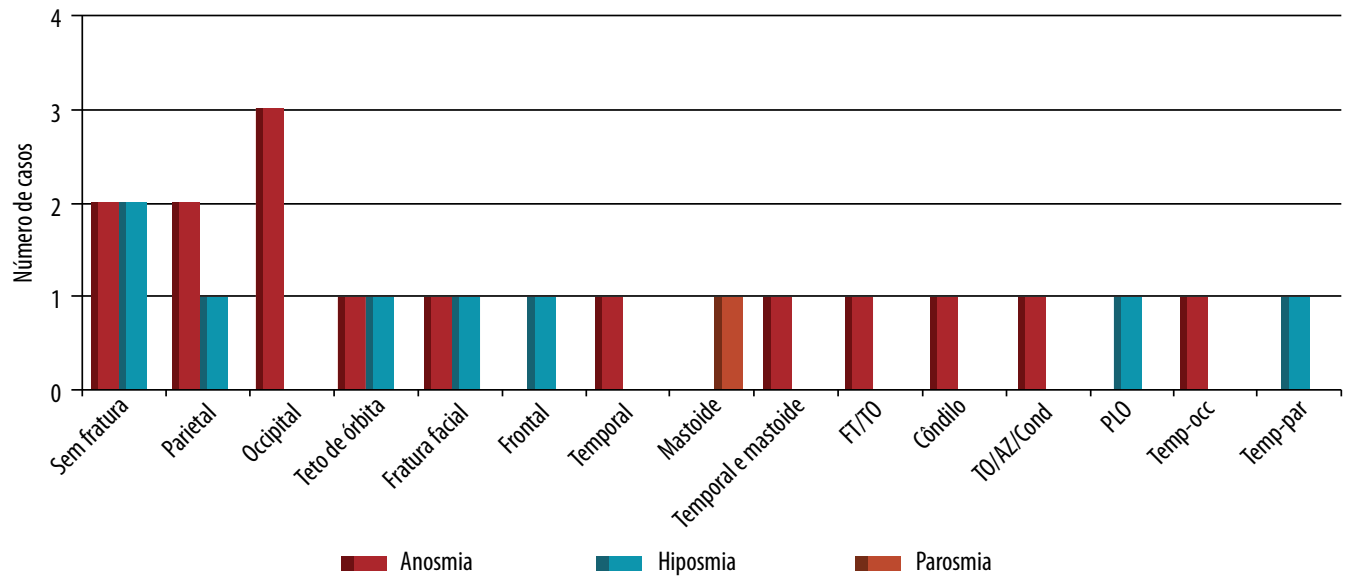

Figura 2 - Distribuição de frequência das fraturas cranianas.

FT/TO: frontotemporal e teto de órbita; TO/AZ/Cond: teto de órbita, arco zigomático e côndilo occipital; PLO: parede lateral de órbita; Temp-occ: têmporo-occipital; Temp-par: têmporo-parietal. 


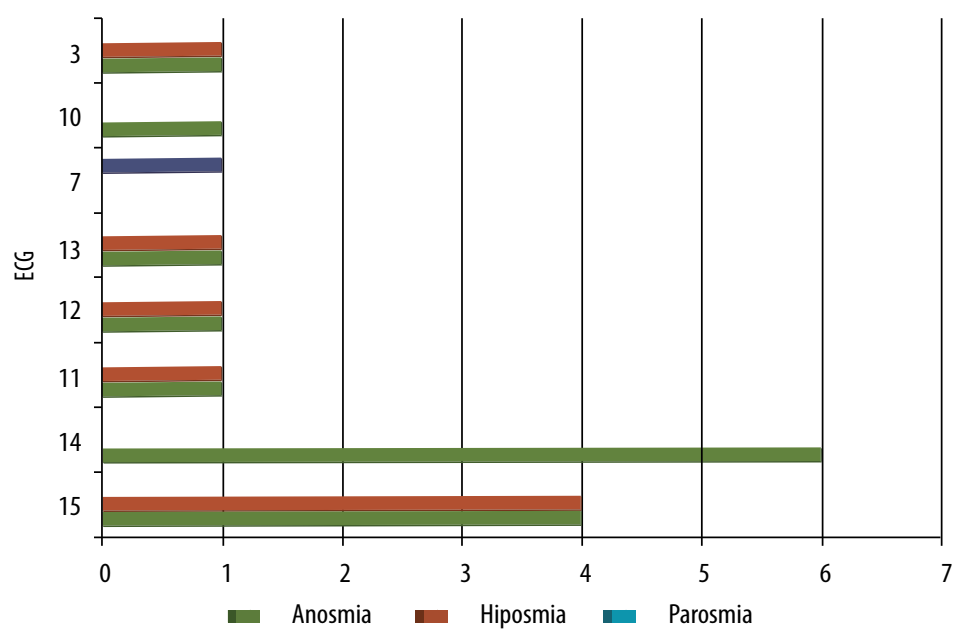

Figura 3 - Distribuição de frequência dos escores da escala de coma de Glasgow na admissão do paciente. ECG: escala de coma de Glasgow.

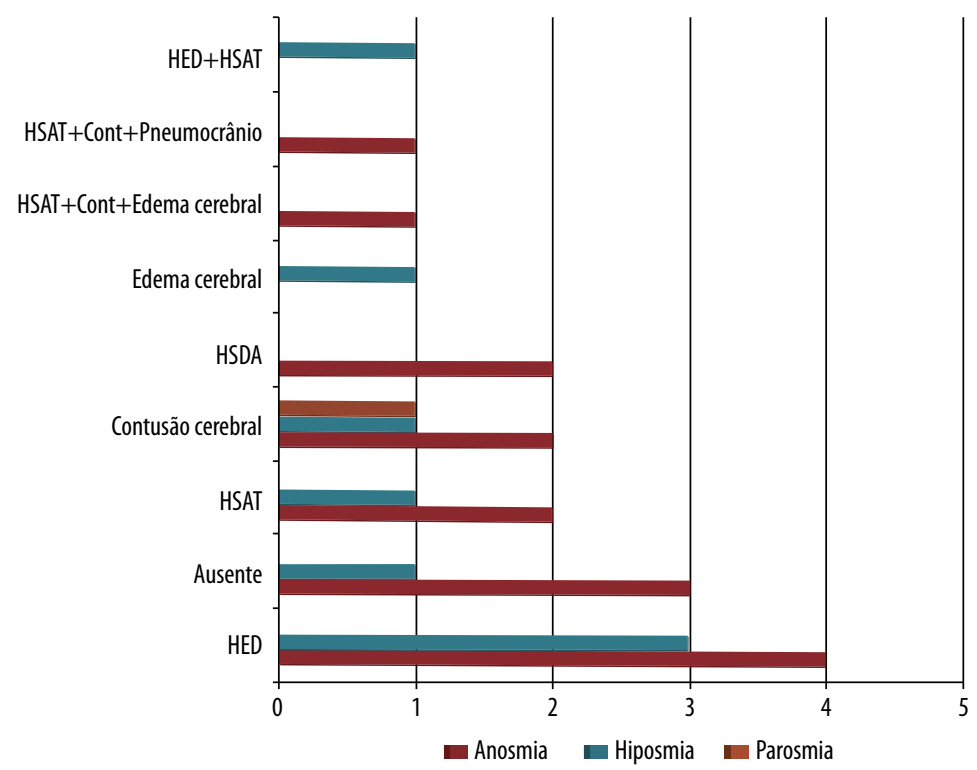

Figura 4 - Distribuição de frequências das lesões intracranianas.

HED: hematoma extradural; HSAT: hemorragia subaracnoide traumática; HSDA: hematoma subdural agudo; Cont: contusão cerebral.

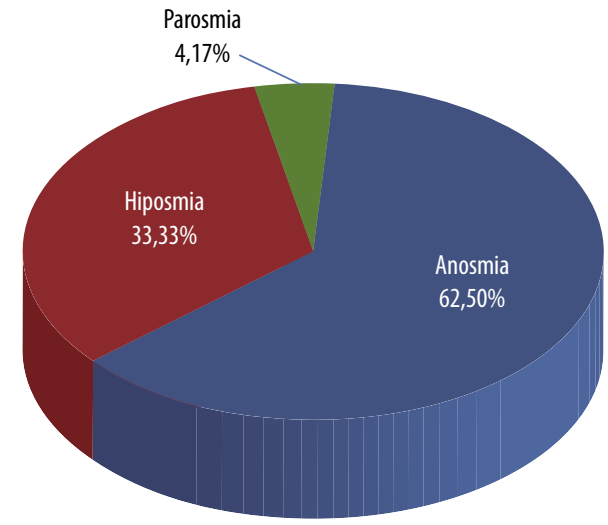

Figura 5 - Distribuição de frequências das lesões do nervo olfatório. 


\section{Anatomia}

O nervo olfatório é responsável pela transmissão dos estímulos olfatórios do epitélio olfatório, localizado na cavidade nasal (porção superior), para o cérebro. ${ }^{3}$ As estruturas cerebrais envolvidas na olfação são coletivamente chamadas de rinencéfalo. O primeiro neurônio sensitivo da via olfatória é bipolar e faz parte do epitélio olfatório (neuroepitélio), localizado na porção superior da cavidade nasal, mais precisamente, estendendo-se da concha nasal superior ao septo nasal. ${ }^{3}$ As moléculas aromáticas são dissolvidas pela umidade produzida por glândulas secretivas. Assim, o processo periférico do neuroepitélio, que não possui receptores, age como tal. Os neurônios primários transmitem a sensação olfativa por meio de pequenos ramos nervosos (20 em média) que atravessam a lâmina crivosa do osso etmoide (Figura 6) para fazer sinapse com o segundo neurônio, localizado no bulbo olfatório (Figura 7).

O bulbo olfatório constitui um alargamento rostral do trato olfatório e é formado por corpos de neurônios, cujos componentes principais são as células mitrais, que se projetam principalmente

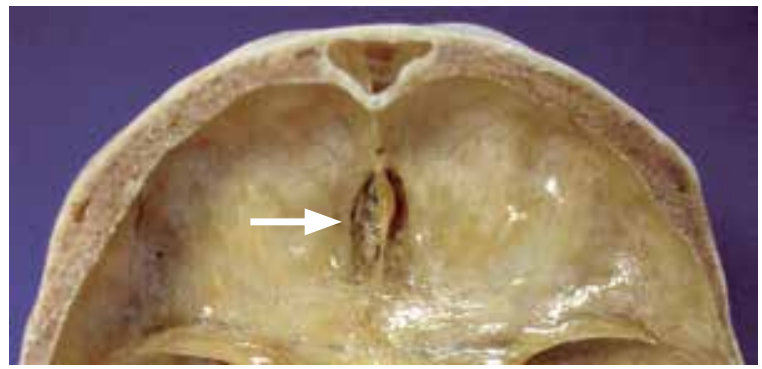

Figura 6 - Lâmina crivosa do osso etmoide (Laboratório de Morfologia da Faculdade de Ciências Médicas da Santa Casa de São Paulo).

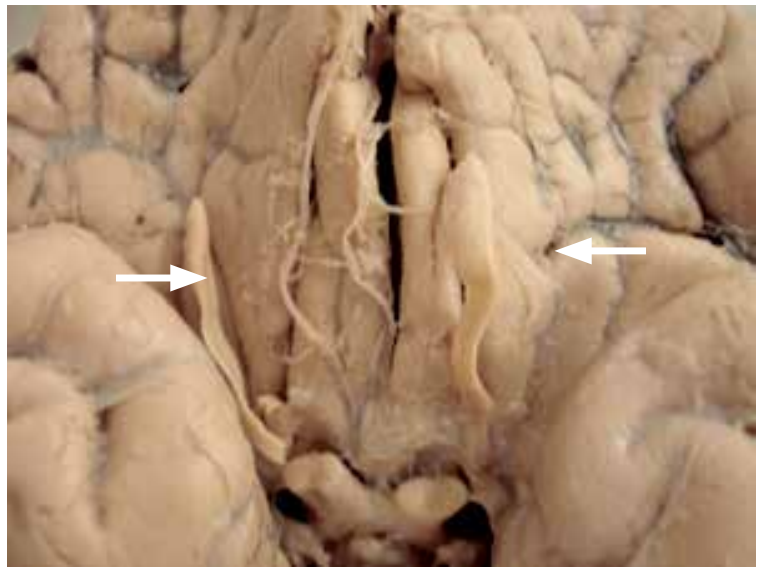

Figura 7 - Nervo olfatório (Laboratório de Morfologia da Faculdade de Ciências Médicas da Santa Casa de São Paulo). para a área olfatória lateral. Há também as células em tufo, cujos axônios projetam-se para o núcleo olfatório anterior a áreas olfatórias lateral, intermédia e medial. ${ }^{4}$

Do bulbo olfatório, as fibras pós-sinápticas formam o trato e o trígono olfatório, a partir do qual se formam as estrias olfatórias lateral, intermédia e medial.

Ramos colaterais das fibras pós-sinápticas terminam em um pequeno grupo denominado núcleo olfatório anterior, localizado entre o bulbo e o trato olfatório. A partir desse núcleo, fibras pós-sinápticas seguem com os processos centrais das células mitrais e em tufo ou cruzam a comissura anterior para alcançar o bulbo olfatório contralateral.

A maior parte dos axônios do trato olfatório alcança a área olfatória lateral (primária) por meio da estria olfatória lateral. ${ }^{4}$

A área olfatória lateral é constituída de córtex do úncus e área entorrinal (parte anterior do giro para-hipocampal), límen insular e corpo amigdaloide. Essas três estruturas são conhecidas em conjunto como área piriforme.

A estria olfatória intermédia é composta por um número limitado de neurônios que deixam o trígono olfatório para alcançar a substância perfurada anterior, a qual forma a área olfatória intermédia.

A estria olfatória medial é formada por axônios do trato olfatório que seguem para a área olfatória medial (septal) na região subcalosa da superfície medial do lobo frontal. ${ }^{4}$ Acredita-se que essa área possa mediar a resposta emocional a odores por meio de suas conexões com o sistema límbico. As três áreas olfatórias emitem fibras para centros autonômicos para respostas viscerais como salivação em resposta a um odor agradável ou náusea quando da exposição a um odor desagradável. ${ }^{4}$

As vias principais são: a) feixe telencefálico medial, que conduz informações das três áreas olfatórias ao hipotálamo; b) estria medular do tálamo, conduzindo impulsos ao trígono das habênulas (epitálamo); c) estria terminal, conduzindo informações do núcleo amigdaloide ao hipotálamo anterior e área pré-óptica.

Dos núcleos habenulares e hipotálamo, a informação é passada à formação reticular e núcleos de nervos cranianos responsáveis por respostas viscerais, como núcleos salivatórios superior e inferior e dorsal do vago. ${ }^{4}$

A olfação está interligada à gustação, porém as bases anatômicas de suas conexões são pouco conhecidas. ${ }^{4,5}$ 


\section{Semiologia}

$\mathrm{Na}$ rotina do consultório de Neurologia o exame do primeiro par craniano não é usual; na verdade raramente é feito, ficando indicado para casos precisos como trauma de crânio. ${ }^{6,7}$

Para realizar o exame, é necessário algo que emita odor conhecido, por exemplo, o café, a canela e a hortelã. Explica-se para o paciente o que será feito e coloca-se a substância diante de uma das narinas (sendo necessário obstruir a outra), perguntando-se se há reconhecimento do odor. Repete-se o processo na outra narina.

$O$ paciente pode não reconhecer o odor em uma das narinas, o que nos faz pensar em lesão de bulbo, que ocorre no trauma craniano em lesões por fratura de base de crânio. As lesões bilaterais podem decorrer de lesões bilaterais do nervo, entretanto terão que ser descartadas lesões primárias do nervo olfatório ou ainda processos inflamatórios das cavidades nasais e fístulas liquóricas nasais.,

Amoore apud Griffith ${ }^{7}$ afirma que a mucosa olfatória humana pode distinguir os seguintes odores: cânfora, pungente, floral, etéreo, hortelã, almíscar e pútrido.

Para a avaliação da função do nervo olfatório, solicitamos a colaboração do paciente para que identificasse o odor de uma substância conhecida e não revelada previamente, colocada no interior de um tubo de ensaio e impossibilitando-o de visualizar as características visuais da substância.

Aproximamos o tubo de ensaio a uma narina, provocando leve pressão na narina contralateral para a obstrução dela. Alterações alérgicas, coriza, fístula liquórica e obstruções nasais foram descartadas previamente ao teste. Utilizamos pó de café e canela ou pó de café e hortelã. Após a realização do teste em uma das narinas, repetia-se o processo contralateralmente.

Tomamos o cuidado de determinar intervalos de 30 segundos entre o teste de uma narina e outra para que não houvesse memorização da substância testada.

\section{Discussão}

Hagan $^{9}$ define a lesão traumática do olfatório como a perda da função olfativa decorrente de trauma craniano e que não envolve diretamente o nariz ou o epitélio olfativo, mas sim as fibras do nervo olfatório na região superior à lâmina crivosa do etmoide (Figura 6).
Segundo esse autor, a lesão traumática do primeiro nervo está presente em $3 \%$ a $5 \%$ de todos os casos de TCE e aumenta para $15 \%$ a $20 \%$ quando a contusão cerebral está associada. De acordo com suas observações, anosmia completa é raramente reversível, porém a hiposmia pós-traumática tende a melhorar no decorrer do tempo, devendo-se acrescentar que todos os pacientes de sua série foram vítimas de traumas com alto valor cinético.

Acredita-se que a lesão na condução nervosa decorra da lesão sofrida pelo suprimento sanguíneo ao nervo. ${ }^{6}$ As lesões podem ser reversíveis ou irreversíveis.

Patel et al. ${ }^{1}$ relatam estudo em 99 pacientes com lesões traumáticas de nervos cranianos, sendo a maioria portadora de lesões leves.

Nas lesões traumáticas dos nervos cranianos, a biomecânica do trauma está diretamente ligada ao prognóstico de recuperação funcional do nervo.

Além de serem lesados diretamente pelo trauma, podem ser lesados por reação tecidual presente em fraturas, aumento na pressão intracraniana e meningite.

A lesão do nervo olfatório deve ser suspeitada na presença de equimose periorbitária, fístula liquórica nasal, epistaxe, fratura nasal (Figura 8) e proptose. ${ }^{2}$

A anosmia é mais comum no trauma occipital, quando comparada ao trauma frontal. ${ }^{5,7}$ É decorrente do contragolpe sofrido pela região basal dos lobos frontais (Figuras 9 e 10). A frequência da anosmia é proporcional à intensidade do trauma.

Sumner ${ }^{10}$ afirma que a primeira descrição de lesão traumática de nervo olfatório foi realizada por Hughlings Jackson em 1864 e que a incidência de lesão olfatória ocorreu em $7 \%$ dos casos, aumentando para $30 \%$ quando o trauma for grave ou incluir lesões na fossa craniana anterior. Também pode ser consequência de traumas que não levam a alterações do nível de consciência.

Leigh $^{3}$ encontrou $5 \%$ de lesão de nervo olfatório em traumas de crânio, enquanto Sumner ${ }^{5}$ afirma incidência de $4 \%$ em sua casuística.

Kindler apud Sumner ${ }^{5}$ afirma que a lesão do nervo olfatório é independente do sítio ou da intensidade do trauma, enfatizando a importância dessa lesão em profissionais de cozinha, perfumarias e provadores de café.

Goland ${ }^{11}$ relata lesão de nervo olfatório em três pacientes com trauma e fraturas occipitais e outros três com fraturas parietais; nesses casos, a anosmia era unilateral e a hiposmia era contralateral à fratura, o que é atribuído ao contragolpe.

Leigh $^{3}$ apresentou a primeira grande série de pacientes com anosmia em estudo de 1.000 pacien- 
tes com TCE. Setenta e dois pacientes apresentaram anosmia, dos quais apenas seis recuperaram a função olfativa, enquanto 12 desenvolveram parosmia. Ele acreditava que a lesão do I nervo estivesse relacionada à intensidade do trauma.

Segundo Kottmeyer apud Sumner, ${ }^{10}$ somente o trauma occipital poderia causar anosmia sem fraturas, enquanto os traumas frontais somente $o$ fariam na presença de fraturas.

A maioria dos pacientes não apresentava lesão detectável no primeiro exame, e sim durante exame no acompanhamento ambulatorial. Isso pode ser explicado pela ausência de processo edematoso na fase aguda, que foi se desenvolvendo ao longo do tempo, provocando diminuição na sensibilidade olfatória, muitas vezes não percebida pelo próprio paciente e somente detectada quando da aplicação de testes específicos.

Notamos que a maior parte dos pacientes com lesão de nervo olfatório apresentava traços de fratura craniana. A fratura da lâmina crivosa do osso etmoide ocorre em $70 \%$ dos casos, ${ }^{3}$ porém lesões estabelecidas do nervo olfatório também foram encontradas em traumas occipitais (três casos), o que pode ser explicado pelo processo de desaceleração do encéfalo e movimento de tosquia das raízes olfatórias na placa crivosa ou avulsão do trato olfatório.

Na série de Hughes, ${ }^{6}$ em $65,8 \%$ das lesões o impacto foi na região frontal e $8,9 \%$ em região occipital, sendo as lesões temporais e parietais responsáveis por 14,6\% das lesões do olfatório.

Para Schechter e Henkin, ${ }^{12}$ a lesão traumática do nervo olfatório independe da intensidade do trauma, da presença ou ausência de amnésia pós-traumática, da presença de fraturas e da localização do trauma. Contudo, a alta incidência de trauma occipital sugere que trauma nessa região possa predispor a um maior número de alterações olfativas e gustativas. Acrescenta ainda que são alterações que costumam aparecer imediatamente ao trauma, embora tenha observado um reduzido número de alterações tardias (vários meses após o trauma).

Hagan $^{9}$ recomenda o uso de café, canela, água de rosas, cânfora, lavanda, óleo de cravo e menta. Com substâncias ácidas (vinagre), obteve irritação da cavidade nasal, contraindicando o seu uso. Para testar a gustação, recomenda o uso de sal (cloreto de sódio 5\%) e açúcar (sacarose 10\%), além de substâncias amargas (quinino 1\%) e ácidas (ácido cítrico 5\%).

Um teste importante para se determinar a veracidade das afirmações do paciente no tocante à perda olfativa é verificar a integridade do nervo trigêmeo com substâncias aromáticas voláteis.
Na integridade do trigêmeo, o indivíduo será capaz de reconhecê-las, assim como identificar substâncias ácidas (vinagre) quando em contato com a língua.

A perda da olfação costuma não ser importante para o bem-estar do paciente, a não ser em casos em que o indivíduo trabalhe em profissões que exijam o reconhecimento de diferentes odores ou em situações de trabalho com gases, onde um vazamento poderá trazer riscos para o indivíduo. ${ }^{3}$

Embora a anosmia possa parecer completa, os pacientes relatam a preservação do paladar, que depende muito do aroma. Isso pode ser explicado nos casos de perda parcial da olfação por meio de aromas surgidos na nasofaringe.

Segundo Bhatoe, ${ }^{2} 40 \%$ dos pacientes com lesão traumática de nervo olfatório observam recuperação funcional nos primeiros três meses após a lesão. A recuperação precoce implica resolução de efeitos compressivos locais, como hematoma e edema ou contusão, enquanto a recuperação tardia demonstra processo de regeneração de neurônios da mucosa olfatória em direção aos bulbos olfatórios.

Hughes $^{6}$ afirma que o local mais frequente de lesão do nervo olfatório ocorre na região superior da lâmina crivosa do etmoide, onde a laceração de fibras olfatórias, contusão e hemorragia ocorrem em decorrência de rápidas acelerações e desacelerações sofridas pelo encéfalo. Porém, esse mecanismo de ação não explica as alterações gustativas advindas do trauma.

Deve-se considerar que a lesão do nervo também pode ocorrer em outros pontos da via olfativa; Goland $^{11}$ afirma que o trauma occipital levaria a um impacto das estrias olfatórias contra a asa menor do osso esfenoide.

Holbourn apud Sumner ${ }^{5}$ afirma, por meio de modelos experimentais com gelatina, que o trauma occipital pode causar cisalhamento dos filamentos do nervo olfatório, apesar desse cisalhamento ser mínimo nas vizinhanças da base do encéfalo, poupando os nervos cranianos do movimento rotacional, porém a maior parte da energia cinética seria transmitida aos lobos temporais, podendo-se lesar outro ponto da via olfatória.

Goland $^{11}$ acredita que a lesão possa ocorrer na estria olfatória lateral, lacerada pelas margens afiadas da asa menor do esfenoide, porém a maior parte das lesões ocorre por traumas occipitais ou frontais associados a grandes alterações de aceleração. ${ }^{13}$

Collet apud Hagan ${ }^{9}$ atribuiu a alteração da função olfativa pós-traumática à lesão do bulbo e filamentos olfatórios. 
Encontramos apenas um caso de parosmia, em que a sensação olfativa é distorcida, geralmente não prazerosa e ocorre, na maioria das vezes, na lesão do lobo temporal.

Sumner ${ }^{5}$ relata que a melhora da função olfativa ocorre em um terço dos casos e correlaciona a melhora dessa função com o tempo de amnésia pós-traumática, alegando que indivíduos com amnésia pós-traumática superior a 24 horas terão anosmia definitiva em $90 \%$ dos casos. Porém, quando a melhora da função ocorre, geralmente se faz por completo.

Além disso, o aparecimento da parosmia também não demonstra qualquer relação com a intensidade do trauma.

Patel et al. ${ }^{1}$ relatam em sua série a porcentagem de $0,88 \%$ para as disfunções pós-traumáticas do nervo olfatório, relacionadas a trauma craniano leve e presença de fístula liquórica. A minoria dos pacientes apresentou melhora da função olfatória nos 18 meses de seguimento ambulatorial.

Clark e Dodge ${ }^{13}$ afirmam que a gustação é uma síntese de sensações derivadas dos nervos olfatórios, papilas gustativas e outras terminações sensitivas localizadas o interior da boca. Em outro trabalho, ${ }^{14}$ publica que indivíduos com anosmia podem ainda ter a sensibilidade gustativa preservada, pois os componentes extraolfatórios da gustação desempenham papel importante na manutenção dela e incluem sensações somáticas bucais, nasofaríngeas, visuais, auditivas e de memória, assim como o estado psicológico do indivíduo ao comer.

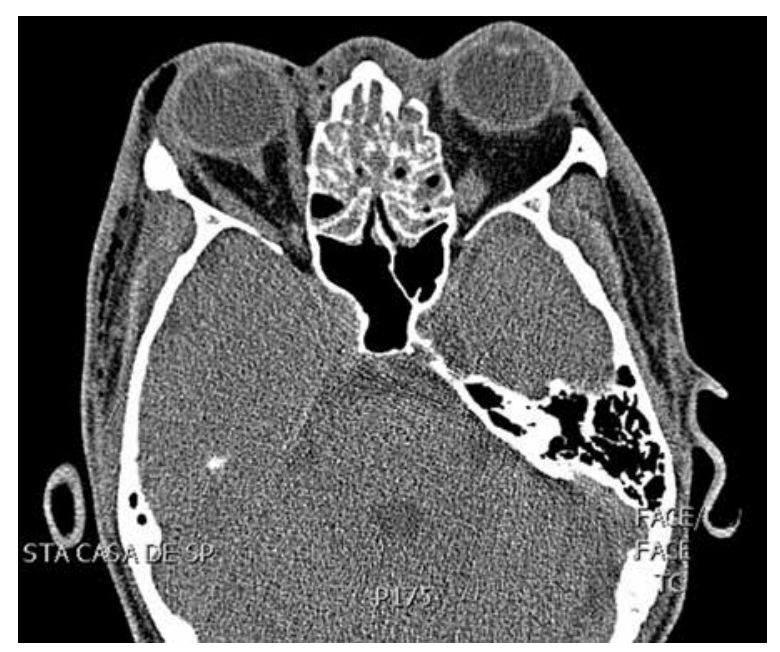

Figura 8 - Tomografia de crânio evidenciando fratura nasal.
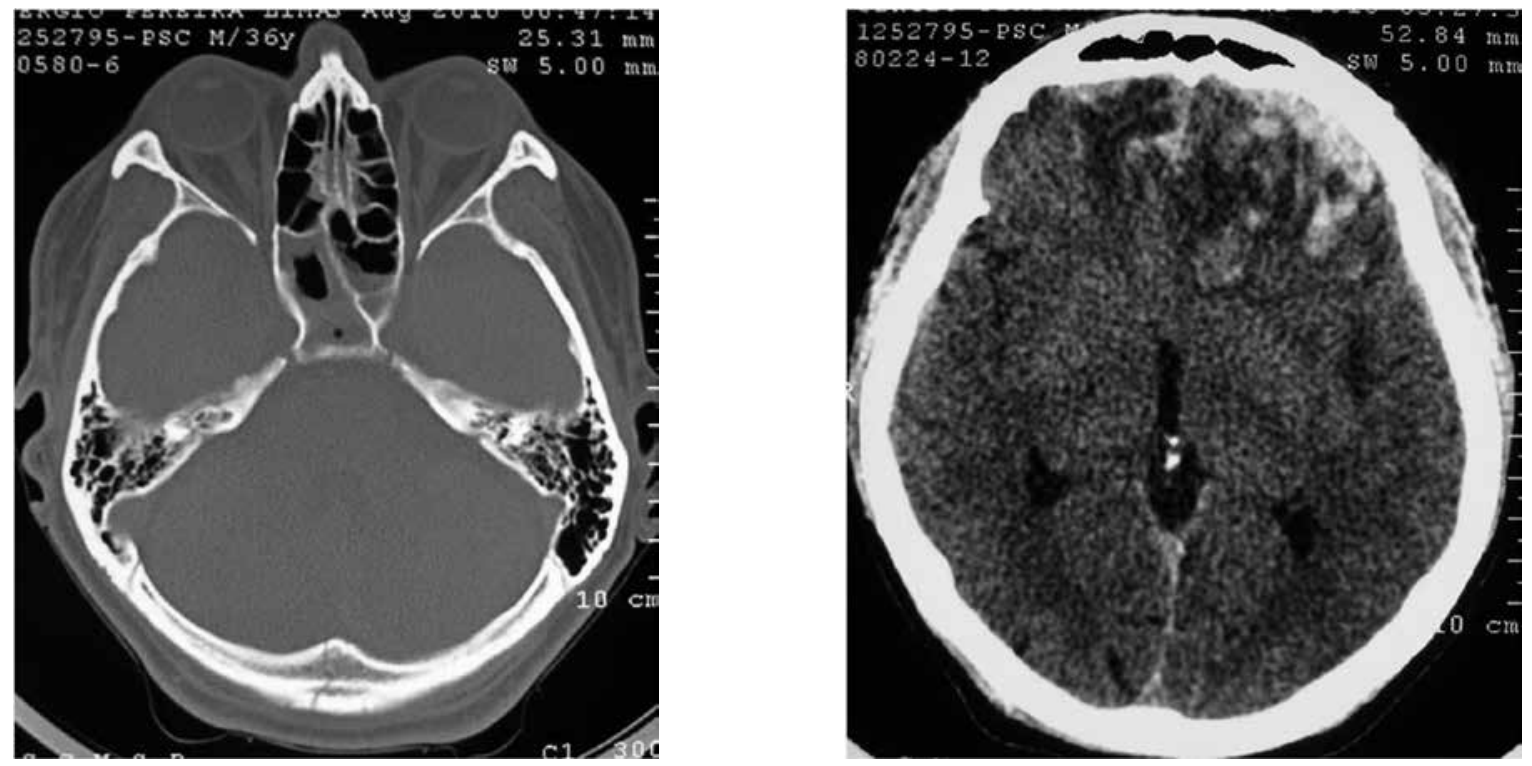

Figura 9 - Fratura occipital e contusão frontal em contragolpe em paciente com lesão de nervo olfatório. 

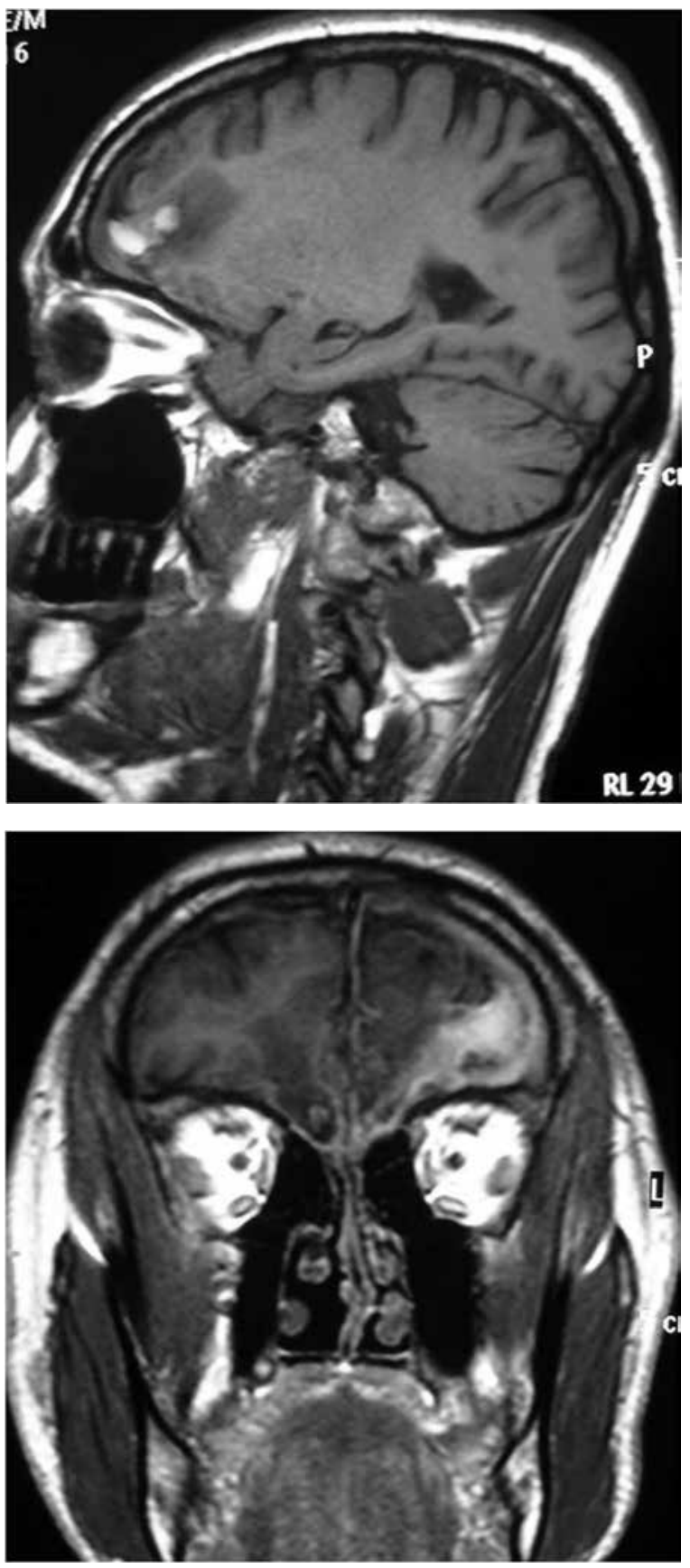

Figura 10 - Contusão frontal em contragolpe em paciente com lesão de nervo olfatório.

A recuperação da função olfatória varia de $8 \%$ a 39\% nos pacientes com anosmia pós-traumática. ${ }^{5,79}$

As alterações gustativas pós-traumáticas (hipogeusia e disgeusia) têm recebido muito menos atenção e ocorrem menos frequentemente em relação às alterações olfativas; a incidência de lesão chega até $4 \%$ dos pacientes. ${ }^{12}$ Evidenciaram-se alterações gustativas somente em dois casos com lesão de nervo olfatório.
Griffith $^{7}$ afirma que a hiperosmia tem rara ocorrência e tem etiologia psicogênica.

Geralmente as alterações gustativas acompanham as alterações olfativas e na maioria dos casos regridem espontaneamente, sugerindo que a melhora gustativa ocorra muito mais frequentemente que a melhora olfativa. Não há relação entre a severidade do trauma e o aparecimento de lesões gustativas, ${ }^{12}$ pois mesmo em traumas cranianos leves elas podem ocorrer, e seu início pode ser de ocorrência tardia (meses após o trauma).

Quando são consideradas em conjunto, ambas as lesões (olfatória e gustativa) atingem entre 6\% e $33 \%$ dos indivíduos com TCE. A etiologia da disgeusia ou ageusia pós-traumática é obscura. Sugere-se que sejam devidas à irritação ou destruição do nervo olfatório. Leigh ${ }^{3}$ sugere que represente um estágio de recuperação da anosmia. Deve-se observar que alguns casos de alterações gustativas podem ocorrer na ausência de alterações olfativas. ${ }^{12}$ Alguns pacientes com anosmia e hipogeusia pós-traumáticas exibem alterações no metabolismo do zinco semelhantes a pacientes com perdas de zinco e que apresentam alterações gustativas. ${ }^{12}$ Existe aumento na concentração sérica de zinco (77+/-3 microgramas/100 ml) associada à diminuição na concentração sérica de cobre (99 +/-2 microgramas/100 ml).

Cohen et al. ${ }^{15}$ demonstraram que alterações no metabolismo do zinco e do cobre (hipozincemia e normocupremia; hiperzincúria e hipercuprúria) podem causar alterações gustativas e olfativas e que a reposição do zinco tende a melhorar os sintomas em pacientes vítimas de queimaduras. Porém, não fornecem uma explicação para o aparecimento da hipo ou ageusia.

Portanto, propõe que o mecanismo de aparecimento das alterações gustativas decorra de alterações no metabolismo do zinco.

Segundo Paskind, ${ }^{16}$ casos de parosmia são descritos em meningites da base do crânio, trauma frontais, aterosclerose cerebral e processos infecciosos que envolvem a cavidade nasal. É difícil entender por que a parosmia contínua seja tão rara. Porém, a anosmia em lesões frontais é relativamente comum (meningiomas da goteira olfatória).

Como a anosmia é um sintoma relacionado à destruição e a parosmia está relacionada à irritação da via olfatória, ele acredita que a parosmia possa anteceder a anosmia. ${ }^{16}$

Ele sugere, portanto, que a parosmia seja pesquisada em pacientes que já apresentem anosmia, afirmando que a parosmia pode ser um sintoma precoce de lesão intracraniana. 
Zusho $^{17}$ relata incidência de lesão de nervo olfatório de 4,2\% em sua série, incluídos casos de anosmia e hiposmia.

Em 44\% dos casos houve a presença de fraturas cranianas ou faciais, sendo a região occipital o local mais comum de traumas, seguidas dos traumas faciais e frontais.

Relata não haver grau de dependência entre a intensidade do trauma, presença ou ausência de fraturas e grau da disfunção olfativa.

Atribui o déficit olfativo traumático a quatro grandes etiologias:

- Distúrbio respiratório - devido a traumas faciais, principalmente aqueles com acometimento nasal, levando à deformidade da cavidade nasal. A hiposmia é mais frequente que a anosmia.

- Distúrbios epiteliais: por lesão direta do epitélio olfativo ou por lesão indireta decorrente de alterações circulatórias por alterações do sistema nervoso autônomo ou lesão em tronco encefálico.

- Distúrbio dos nervos olfatórios: o local mais comum de lesão é a região superior da placa crivosa do etmoide (lesão dos filetes nervosos, presença de hematomas e contusões devidas à aceleração e desaceleração do encéfalo).

- Distúrbio central: qualquer lesão que atinja bulbos, tratos ou córtex entorrinal.

Ichihara apud Zucho ${ }^{17}$ relata que a maioria das lesões olfativas traumáticas ocorre por trauma occipital.

Sumner ${ }^{18}$ afirma que as alterações gustativas sejam decorrentes da lesão olfativa e que não se é dada a devida importância a esse sintoma. A ageusia associada à anosmia pode ocorrer em traumas com alta ou baixa energia cinética.

Griffith $^{7}$ afirma que a ageusia é rara quando decorrente de trauma, uma vez que haveria necessidade de lesão dos três nervos responsáveis pela condução dessa sensibilidade (VII, IX e X).

A duração da ageusia também independe da intensidade do trauma. O prognóstico para a melhora da função gustativa é melhor que o da função olfati$\mathrm{va}^{18}$ e seu início é mais precoce. Durante esse período, pode haver descrição de parosmia ou parageusia.

A melhora da função gustativa é lenta e progressiva (2 semanas a 18 meses, segundo Sumner), ${ }^{18}$ iniciando-se, geralmente, pelo sabor doce, sendo seguido pelo salgado, ácido e amargo.

Rotch apud Sumner ${ }^{18}$ descreve paciente vítima de queda de altura e que apresentou anosmia e ageusia, porém mantendo intactas as sensações térmico-dolorosas e táteis da língua.
É difícil ter-se uma estatística precisa acerca da incidência de ageusia, pois o exame raramente é realizado e o seu aparecimento é tardio. Acredita-se que sua incidência seja de aproximadamente 5\% dos casos de anosmia pós-traumática e $0,5 \%$ de todos os casos de TCE. ${ }^{19}$

Ageusia não ocorre sem anosmia. Portanto, para se justificar ambos os achados, o trauma deveria envolver ambos os nervos olfatórios, os dois nervos linguais (ou corda do tímpano) e os dois nervos glossofaríngeos.

Porém, a lesão ocorre mesmo em traumas de pequena intensidade, não levando à lesão dessas estruturas.

Ferrier apud Sumner ${ }^{18}$ propôs mecanismo que envolve a porção inferior do lobo têmporo-esfenoidal, onde os centros gustativos e olfativos estão em íntima relação (subiculum).

Mifka apud Sumner ${ }^{18}$ considera que ambas as lesões ocorram somente em indivíduos que possuam inervação anômala da língua, cujas fibras gustativas dirijam-se diretamente para o nervo glossofaríngeo. Traumas poderiam afetar simultaneamente a placa crivosa do etmoide e o forame jugular, especialmente na presença de fraturas basais.

Do ponto de vista histológico, Hasegawa et al. ${ }^{20}$ afirmam que na fase inicial da lesão ocorre a degeneração das vesículas olfatórias, com desaparecimento dos cílios sem alterações das células basais.

Numa fase tardia há ausência completa de vesículas e cílios associada a presença de corpos basais nas vesículas e desorganização do arranjo celular epitelial, conferindo aparência atrófica com afilamento da espessura mucosa, incluindo, ainda, achados de tecido fibroso que auxiliam na desorganização estrutural. Essas alterações são proporcionais à intensidade do trauma.

As células olfativas degeneram-se precocemente após a lesão do nervo olfatório, porém o epitélio olfatório pode regenerar-se a partir das células basais. ${ }^{20}$

Após o trauma que envolve a lesão dos filamentos do nervo olfatório, geralmente ocorrem processo de regeneração e fibrose que envolvem a placa crivosa do etmoide. Portanto, qualquer atividade regenerativa do epitélio olfativo na tentativa de reestabelecer sinapses com os nervos olfatórios (células mitrais) fica prejudicada, dificultando a recuperação da função. $\mathrm{O}$ axônio é defletido e adquire uma aparência espiralada e começa a sofrer processo de degeneração, fazendo com que as células receptoras enviem outros axônios na tentativa de estabelecer contato com o bulbo olfatório. ${ }^{19}$ 
Jafek et al. ${ }^{21}$ realizaram biópsias da mucosa olfatória em pacientes com lesão traumática de nervo olfatório e fizeram análise ultraestrutural dos achados. O epitélio olfatório normal é colunar pseudoestratificado com quatro tipos distintos de células: células de suporte, microvilares, basais e células olfatórias receptivas ciliadas (células sensitivas primárias).

No epitélio olfativo pós-traumático há distorção dessas estruturas. O epitélio olfativo é alargado e globoso. Os núcleos celulares são dispersos por todo o epitélio e frequentemente vistos na superfície mucosa.

O epitélio olfativo contém axônios localizados nas imediações da membrana basal e podem estender-se até a superfície mucosa. Há vários feixes de fibras nervosas na lâmina própria, abaixo da membrana basal.

Raras vesículas olfatórias são observadas e corpos basais podem ser visualizados em seu interior. Cílios que se projetam das células receptoras são raramente observados. ${ }^{22}$

Schurr ${ }^{19}$ afirma que, em casos de anosmia traumática unilateral, pode-se identificar o local de fístulas liquóricas em localizações difíceis de se determinar.

Lewin et al. ${ }^{22}$ afirmam que a hiposmia pós-traumática decorre de lesões difusas do córtex órbito-frontal e temporal, uma vez que em sua série os pacientes identificavam parcialmente os tipos de odores sem correlacioná-los com fontes que pudessem emiti-los.

\section{Conclusões}

A lesão do nervo olfatório geralmente está associada à fratura craniana.

Lesão do nervo olfatório ocorre em traumas de leve ou moderada intensidade.

Traumas occipitais (contragolpe), parietais, faciais e frontais correspondem aos locais de maior etiologia à lesão do nervo olfatório.

Hematomas extradurais e atropelamentos podem ser causas de lesão da via olfatória.

Hiposmia foi o achado mais comum.

\section{Conflito de interesses}

No presente estudo, não houve qualquer tipo de conflito de interesses.

\section{Referências}

1. Patel P, Kalyanaraman S, Reginald J, Natarajan P, Ganapathy K, Suresh Bapu KR, et al. Post-traumatic cranial nerve injury. IJNT. 2005;2(1):27-32.

2. Bhatoe CHS. Trauma to the cranial nerves. IJNT. 2007;4(2):89-100.

3. Leigh AD. Defects of smell after head injury. Lancet. 1943;244:38-40.

4. Wilson-Pauwels L, Akesson EJ, Stewart PA. Cranial nerves: anatomy and clinical comments. Toronto: BC Decker; 1988.

5. Sumner D. Posttraumatic ageusia. Brain.1964;87:107-20.

6. Hughes B. The results of injury to special parts of the brain and skull. The cranial nerves. In: Rowbotham GF, editor. Acute injuries of the head. Baltimore: Williams \& Wilkins; 1964. p. 408-10.

7. Griffith IP. Abnormalities of smell and taste. Practitioner 1976;217(1302):907-13.

8. Lewin W. Cerebrospinal fluid rhinorrhea in closed head injuries. Br J Surg. 1954;42(171):1-18.

9. Hagan PJ. Posttraumatic anosmia. Arch Otolaryngol. 1967;85:107-11.

10. Sumner D. Disturbance of senses of smell and taste after head injuries. In: Vinken PJ, Bruyn BW, editors. Handbook of clinical neurology. Injuries of the brain and skull. Amsterdam: Elsevier; 1976. p. 1-25.

11. Goland PP. Olfactometry in cases of acute head injury. Arch Surg. 1937;35(6)1137-82.

12. Schechter PJ, Henkin RI. Abnormalities of taste and smell after head trauma. J Neurol Neurosurg Psychiatry. 1974;37(7):802-10.

13. Clark EC, Dodge HW Jr. Effect of anosmia on the appreciation of flavor. Neurology. 1955;5(9):671-4.

14. Clark EC, Dodge HW Jr. Extraolfactory components of flavor. J Am Med Assoc. 1955;15(18):1721-3.

15. Cohen IK, Schechter PJ, Henkin RI. Hypogeusia, anorexia, and altered zinc metabolism following thermal burnervo JAMA.1973;223(8):914-6.

16. Paskind HA. Parosmia in tumours involvement of olfactory bulbs and nerves. Arch Neurol Psychiatry (Chic). 1935;33:835-8.

17. Zusho H. Post-traumatic anosmia. Arch Otolaryngol. 1982;108(2):90-2.

18. Sumner D. Post-traumatic ageusia. Brain. 1964;87:187-202.

19. Schurr PH. Aberrations of the sense of smell in head injury and cerebral tumors. Proc Roy Soc Med. 1975;68(8):470-2.

20. Hasegawa S, Yamagishi M, Nakano Y. Microscopic studies of human olfactory epithelia following traumatic anosmia. Arch Otorhinolaryngol. 1986;243(2):112-6.

21. Jafek BW, Eller PM, Esses BA, Moran DT. Post-traumatic anosmia. Ultrastructural correlates. Arch Neurol. 1989;46(3):300-4.

22. Levin HS, High WM, Eisenberg HM. Impairment of olfactory recognition after closed head injury. Brain. 1985;108(Pt 3):579-91.

Endereço para correspondência

Luiz Fernando Cannoni

Rua Conselheiro Cotegipe, 543, Belenzinho

03058-000 - São Paulo, SP, Brasil

Telefone: (11) 2796-7113

E-mail: luiz2603@terra.com.br 